\title{
Decreased Intracellular ATP Content and Intact Mitochondrial Energy Generating Capacity in Human Cystinotic Fibroblasts
}

\author{
ELENA N. LEVTCHENKO, MARTIJN J. G. WILMER, ANTOON J. M. JANSSEN, JAN B. KOENDERINK, HENK-JAN VISCH, \\ PETER H. G. M. WILLEMS, ADRIANA DE GRAAF-HESS, HENK J. BLOM, LAMBERTUS P. VAN DEN HEUVEL,
} AND LEO A. MONNENS

Department of Pediatrics [E.N.L., L.P.H, L.A.M.], Laboratory of Pediatrics and Neurology [M.J.G.W., A.J.M.J., H.-J.V., A.G.-H., H.J.B., L.P.H.], Department of Pharmacology and Toxicology [J.B.K.] Department of Biochemistry [H.-J. V., P.H.G.M.W.], Radboud University Nijmegen Medical Center, 6500 HB Nijmegen, The Netherlands

\begin{abstract}
Cystinosis is an autosomal recessive lysosomal storage disorder caused by a defect in the lysosomal cystine carrier cystinosin. Cystinosis is the most common cause of inherited Fanconi syndrome leading to renal failure, in which the pathogenesis is still enigmatic. Based on studies of proximal tubules loaded with cystine dimethyl ester (CDME), altered mitochondrial adenosine triphosphate (ATP) production was proposed to be an underlying pathologic mechanism. Thus far, however, experimental evidence supporting this hypothesis in humans is lacking. In this study, energy metabolism was extensively investigated in primary fibroblasts derived from eight healthy subjects and eight patients with cystinosis. Patient's fibroblasts accumulated marked amounts of cystine and displayed a significant decrease in intracellular ATP content. Remarkably, overall energy-generating capacity, activity of respiratory chain complexes, ouabain-dependent rubidium uptake reflecting Na,K-ATPase activity, and bradykinin-stimulated mitochondrial ATP production were all normal in these cells. In conclusion, the data presented demonstrate that mitochondrial energy-generating capacity and $\mathrm{Na}, \mathrm{K}-\mathrm{ATPase}$ activity are intact in cultured cystinotic fibroblasts, thus questioning the idea of altered mitochondrial ATP synthesis as a keystone for the pathogenesis of cystinosis. (Pediatr Res 59: 287-292, 2006)
\end{abstract}

$\mathrm{C}^{\mathrm{y}}$ ystinosis is an autosomal recessive lysosomal storage disorder caused by a defect in the lysosomal cystine carrier cystinosin, encoded by the CTNS gene (17p13) (1). Intralysosomal accumulation of cystine virtually in all tissues leads to a multiorgan disease with kidneys being clinically first affected. Patients with cystinosis mostly present with generalized proximal tubular dysfunction (Fanconi syndrome) during the first year of life and, when untreated with the cystine-depleting agent cysteamine, develop end-stage renal disease before the age of $10 \mathrm{y}$ (2).

Because proximal tubular cells are highly metabolic active (3), the appearance of Fanconi syndrome as a first clinical sign in cystinosis points to disturbances in energy metabolism in these patients. This idea is substantiated by the occurrence of

Received June 2, 2005; accepted September 30, 2005.

Correspondence: Elena N. Levtchenko, M.D., Department of Pediatric Nephrology, Radboud University Nijmegen Medical Center, P.O. 9101, 6500 HB Nijmegen, The Netherlands; e-mail: e.levtchenko@cukz.umcn.nl

This study was supported by the Dutch Kidney Foundation (grant PC-106).

DOI: 10.1203/01.pdr.0000196334.46940.54
Fanconi syndrome in patients with mitochondrial disorders (4).

Although lysosomal accumulation of cystine in cystinosis was demonstrated already in the 1960s (5), studies on the pathogenesis of this disease were initially hampered by the absence of a proper in vitro model of lysosomal cystine accumulation. This issue was solved with the introduction of dimethyl esters of amino acids, which readily passed the lysosomal membrane and, once inside the organelle, were rapidly degraded by lysosomal hydrolases to yield free amino acid and methanol thus allowing amino acid loading of the lysosomes $(6,7)$. CDME loading of intact leukocytes, cultured lymphoblasts, and fibroblasts established defective cystine exodus from the lysosomes as basic defect in cystinosis $(8-10)$.

Subsequently, CDME loading of proximal tubular cells was used for studying the pathogenesis of Fanconi syndrome in cystinosis. Foreman et al. (11) demonstrated that incubation of rat cortical tubules with CDME increased intracellular cystine concentrations to values comparable to those measured in patients with cystinosis and inhibited active amino acid and glucose transport. CDME loading of rabbit proximal tubules perfused in vitro resulted in a decreased transepithelial potential difference and inhibition of volume absorption and active glucose and bicarbonate transport, mimicking renal Fanconi syndrome in cystinosis (12).

ATP depletion was postulated to be responsible for inhibition of active transport in proximal tubular cells as dramatic decreases in ATP content and mitochondrial respiration rate were demonstrated after CDME loading $(13,14)$. Because most proximal tubular transport is sodium coupled, less fuel for the Na,K-ATPase on the basolateral membrane will lower the sodium electrochemical gradient, thus inhibiting transport across the apical membrane. Consistent with this idea, cystineloaded porcine epithelial tubular cells (LLC-PK1) showed a diminished activity of Na,K-ATPase, demonstrated by re-

Abbreviations: CDME, cystine dimethyl ester; COX, cytochrome $c$ oxidase; CS, citrate synthase; 2-DOG, 2-deoxyglucose; OXPHOS, oxidative phosphorylation; SIA, sodium iodoacetate 
duced rubidium uptake, leading to increased sodium and decreased potassium concentrations inside the cells (15).

Although ATP depletion as a keystone for the pathogenesis of cystinosis is well documented in the CDME loading model, it has not yet been proved in human cystinotic tissues. Furthermore, the possible link between intralysosomal cystine accumulation and ATP depletion is still unknown.

Cultured cystinotic skin fibroblasts are known to accumulate cystine (16) and are easily available via skin biopsy in patients with cystinosis. Because a metabolic defect caused by cystine accumulation has to be present in all body tissues, we used cystinotic fibroblasts to investigate the energy metabolism in cystinosis. The latter was done by determining total intracellular ATP content; overall mitochondrial energygenerating capacity; activity of mitochondrial respiratory chain complexes I, II, III, and IV; maximal bradykininstimulated mitochondrial ATP production; and ouabaindependent rubidium uptake in primary skin fibroblasts derived from patients with cystinosis compared with control fibroblasts.

\section{MATERIALS AND METHODS}

Patients. The study was approved by Institutional Review Board. Skin biopsies were performed after obtaining informed consent from eight patients with cystinosis before starting of cysteamine therapy and in eight healthy subjects. In all patients, cystinosis manifested with renal Fanconi syndrome at the age of 6-18 mo. The diagnosis of cystinosis was made by measuring an elevated cystine content in polymorphonuclear leukocytes $(>0.5 \mathrm{nmol}$ cystine/mg protein) and was confirmed by molecular analysis of CTNS gene in all patients.

Fibroblast cell culture, isolation of polymorphonuclear leukocytes, and intracellular cystine measurements. Skin fibroblasts were cultured in custom made M199 medium with Tween-20 (5 mg/L, GIBCO) supplemented with fetal calf serum (10\%), penicillin (100 U/mL, GIBCO), and streptomycin (100 $\mathrm{U} / \mathrm{mL}$, GIBCO). Polymorphonuclear leukocytes were isolated as described previously (17). Intracellular cystine was determined by high-performance liquid chromatography and expressed as nmol cystine/mg protein (17).

Measurement of total intracellular ATP content. Cystinotic and control fibroblasts were grown to confluence in $75-\mathrm{cm}^{2}$ tissue culture flasks (approximately $1.0 \times 10^{6}$ cells) and detached using trypsin. After washing in phosphate-buffered saline (PBS), cell pellets were divided into two portions for duplicate experiments, shock frozen in liquid $\mathrm{N}_{2}$, and stored at $-80^{\circ} \mathrm{C}$ until use. Before ATP determination, pellets were resuspended on ice in $0.5 \mathrm{~mL}$ cold PBS. A 25 -fold diluted fraction $(25 \mu \mathrm{L})$ of the suspension was transferred to a transparent microtiter plate and ATP was measured using ATP Bioluminescence Assay Kit HSII $\left(\right.$ Roche $^{\mathrm{R}}$ ) according to the instructions of the manufacturer. The residue of the undiluted cell suspension was used for protein determination using the method of Lowry. Data are represented as mean of two separate experiments in nmol ATP/mg protein.

Analysis of metabolic origin of intracellular ATP. To investigate the metabolic origin of intracellular ATP in cultured fibroblasts, we measured the total intracellular ATP content after specific inhibition of glycolysis or the oxidative phosphorylation pathway. To inhibit glycolysis, fibroblasts were incubated for $5 \mathrm{~h}$ at $37^{\circ} \mathrm{C}$ with $0.3 \mathrm{mmol} / \mathrm{L}$ sodium iodoacetate (SIA), an inhibitor of glyceraldehyde-3-phosphate dehydrogenase or $50 \mathrm{mmol} / \mathrm{L} \mathrm{2-de-}$ oxyglucose (2-DOG), a competitor of glucose. Glycolytic activity was determined in a 96-well plate assay by lactate production and was more than $80 \%$ decreased by SIA and DOG compared with the control conditions without the inhibitors (18). The inhibition of mitochondrial ATP production was achieved by incubating fibroblasts for $5 \mathrm{~h}$ at $37^{\circ} \mathrm{C}$ with $1 \mu \mathrm{mol} / \mathrm{L}$ rotenone, which is a specific inhibitor of complex I, or with $1 \mu \mathrm{g} / \mathrm{mL}$ antimycin A, a specific inhibitor of complex III, inhibiting both succinate and NADH-dependent respiration (19). The viability of the cells after the inhibition of glycolysis or mitochondrial ATP production was assessed in a fluorescence assay using resazurin $(0.01 \%)$ as a marker (18). Following incubations with each of the inhibitors and with vehicle controls, intracellular ATP content was determined.

Measurement of overall oxidative phosphorylation (OXPHOS) activity in intact mitochondria. Intact mitochondria were isolated from fresh cultured fibroblasts (approximately $20 \times 10^{6}$ cells) according to Bentlage et al. (20) and suspended in SEF buffer $(0.25 \mathrm{~mol} / \mathrm{L}$ sucrose, $0.01 \mathrm{~mol} / \mathrm{L} \mathrm{KPi}$, $0.002 \mathrm{~mol} / \mathrm{L}$ EDTA, $\mathrm{pH}$ 7.4). Overall energy-generating capacity was determined by measuring ${ }^{14} \mathrm{CO}_{2}$ production rates from oxidation of ${ }^{14} \mathrm{C}$-labeled substrates $\left(\left[1{ }^{1}{ }^{14} \mathrm{C}\right]\right.$-pyruvate, $\left[\mathrm{U}-{ }^{14} \mathrm{C}\right]$-malate, $\left[1,4-{ }^{14} \mathrm{C}\right]$-succinate, and $\left[1-{ }^{14} \mathrm{C}\right.$ 2-oxoglutarate) in combination with several cosubstrates. Oxidation rates were normalized against citrate synthase (CS) activity and expressed as nmol ${ }^{14} \mathrm{CO}_{2} / \mathrm{h}(21)$.

Measurement of the activity of respiratory chain complexes (I-IV) in intact mitochondria. Intact mitochondria were isolated as described above, aliquoted for separate measurements of the respiratory chain complexes, and stored at $-80^{\circ} \mathrm{C}$. With slight modifications, complex I (NADH:Q1 oxidoreductase) activity was determined spectrophotometrically by monitoring NADH oxidation at $340 \mathrm{~nm}$ as described by Fischer et al. (22). Activity of complex III (coenzyme $\mathrm{Q}_{10}$ : cytochrome $c$ oxidoreductase) was determined by measuring the reduction of cytochrome $c$ at $550 \mathrm{~nm}$ with reduced decyl ubiquinone as an artificial substrate according to Bentlage et al. (20). Complex II+III (succinate:cytochrome $c$-oxidoreductase [SCC]) activity was determined spectrophotometrically at $550 \mathrm{~nm}$ by measuring reduction of cytochrome $c$ using succinate as a substrate in the presence of rotenone and $\mathrm{KCN}$ to inhibit complex I activity and eliminate reoxidation of cytochrome $c$, respectively (23). Complex IV (cytochrome $c$ oxidase [COX]) activity was determined by the method described by Cooperstein and Lazarow (24). Mitochondrial citrate synthase (CS) activity was measured by a method described by Srere et al. (25) and expressed as $\mathrm{mU} / \mathrm{mg}^{-1}$ protein. Activities of complexes I, II, and III are expressed as mU/U COX after normalization of the activity of complex IV against that of CS.

Luminescence monitoring of bradykinin stimulated mitochondrial ATP production in intact fibroblasts. To monitor mitochondrial ATP production, 25,000 fibroblasts were seeded on a $13 \times 2$-mm glass coverslip and cultured for $24 \mathrm{~h}$. Cells were then infected with a baculovirus containing the cDNA for mitochondria targeted luciferase generated as described by Visch $e t$ al. (26). The cDNA was kindly provided by Dr. G. A. Rutter (27). After $48 \mathrm{~h}$ of culture in the presence of $1.75 \mathrm{mmol} / \mathrm{L}$ Na-butyrate, the coverslip was placed in the thermostated $\left(37^{\circ} \mathrm{C}\right)$ luminometer and perfused $\left(3 \mathrm{~mL} \cdot \mathrm{min}^{-1}\right)$ with a HEPES-Tris medium $(132 \mathrm{mmol} / \mathrm{L} \mathrm{NaCl}, 4.2 \mathrm{mmol} / \mathrm{L} \mathrm{KCl}, 1 \mathrm{mmol} / \mathrm{L}$ $\mathrm{MgCl}_{2}, 5.5 \mathrm{mmol} / \mathrm{L}$ D-glucose, $10 \mathrm{mmol} / \mathrm{L}$ HEPES, $1 \mathrm{mmol} / \mathrm{L} \mathrm{CaCl}_{2}, \mathrm{pH} 7.4$ ) containing beetle $5 \mu \mathrm{mol} / \mathrm{L}$ luciferin (Promega). Luciferase luminescence was monitored continuously using a custom-built setup that consisted of a lightshielded low-noise photomultiplier tube (PMT) with a built-in H7360-1 amplifier-discriminator (Hamamatsu Photonics K. K., Shizuoka-Ken, Japan). PMT output was monitored in time using a PCI-6601 photon counting board (National Instruments, Austin, TX) coupled with an IBM-compatible computer using custom-written software (Drs. S. P. Srinivas and W. van Driessche, Laboratory of Physiology, K.U. Leuven, Belgium). Light output was recorded at 2-s intervals, after which the traces were smoothed offline by using a 3-point moving average (Origin Pro 6.1, OriginLab Corporation, Northampton, MA). Typically, light output from a coverslip of fibroblasts expressing mitochondrial luciferase was $500-1500$ counts $\cdot \mathrm{s}^{-1}$ with a background of 15 counts $\cdot \mathrm{s}^{-1}$. At the indicated time, $1 \mu \mathrm{mol} / \mathrm{L}$ bradykinin was included in the perfusion medium for maximal stimulation of mitochondrial ATP production. Bradykinin releases $\mathrm{Ca}^{2+}$ from the endoplasmic reticulum leading to a rapid increase in cytosolic and consequently intramitochondrial $\mathrm{Ca}^{2+}$ concentration, which, in turn, leads to an increase in activity of the pyruvate dehydrogenase system, 2-oxoglutarate dehydrogenase, and isocitrate dehydrogenase (28). Results are expressed as the percentage increase in luciferase luminescence.

Measurement of the activity of Na,K-ATPase by $R b^{+}$influx. ${ }^{86}$ Rubidium $\left({ }^{86} \mathrm{Rb}^{+}\right)$, a congener of $\mathrm{K}^{+}$, uptake was measured to determine Na,K-ATPase activity in cystinotic and control fibroblasts as previously described (29). Briefly, cells were grown to $40 \%-60 \%$ confluence in 24 -well plates, washed three times with $\mathrm{Rb}^{+}$-transport medium $(140 \mathrm{mmol} / \mathrm{L}$ choline chloride, $6 \mathrm{mmol} / \mathrm{L} \mathrm{NaCl}, 0.5 \mathrm{mmol} / \mathrm{L} \mathrm{MgCl} 2,5 \mathrm{mmol} / \mathrm{L}$ glucose, $4 \mathrm{mmol} / \mathrm{L} \mathrm{Na-Tris}$ [pH 7.4]) and preincubated in $180 \mu \mathrm{L}$ of this medium with or without $10 \mathrm{mmol} / \mathrm{L}$ ouabain, a specific Na,K-ATPase inhibitor, for $5 \mathrm{~min}$ at $37^{\circ} \mathrm{C}$. Uptake was started by adding $20 \mu \mathrm{L}$ of a mixture of $\mathrm{KCl}(5 \mathrm{mmol} / \mathrm{L})$ and $15 \mu \mathrm{Ci} / \mathrm{mL}^{86} \mathrm{Rb}^{+}(8.6 \mu \mathrm{mol} / \mathrm{L})$, followed by $30 \mathrm{~min}$ of incubation at $37^{\circ} \mathrm{C}$. Then, the medium was removed and cells were washed three times with ice-cold Rb-transport medium. After solubilization in $0.5 \mathrm{~mL} \mathrm{NaOH}$ $(0.2 \mathrm{~mol} / \mathrm{L})$ for $40 \mathrm{~min}, 0.4 \mathrm{~mL}$ was used for liquid scintillation counting (Packerd). Ouabain-sensitive ${ }^{86} \mathrm{Rb}^{+}$uptake was expressed in $\mathrm{nmol} / \mathrm{mg}$ protein/h. Control experiments with $10 \mu \mathrm{mol} / \mathrm{L}$ bumetanide (inhibitor of $\mathrm{Na}^{+}, \mathrm{K}^{+}, 2 \mathrm{Cl}^{-}$cotransporter) showed no significant ouabain-insensitive uptake (data not shown).

Statistical analysis. The Mann-Whitney $U$ test was used for the comparison of values from cystinotic and control cells. The correlation between two 
variables was estimated by a Spearman rank correlation method. The differences were considered statistically significant at $p<0.05$.

\section{RESULTS}

The intracellular cystine content was significantly elevated in cystinotic fibroblasts (median, 4.3 [range, 2.7-5.5] versus median, 0.2 [range, $0.1-0.3$ ] nmol $/ \mathrm{mg}$ protein, $p<0.001$ ).

Data on intracellular ATP content; activity of mitochondrial respiratory chain enzyme complexes I, II, III, and IV; and $\mathrm{Na}, \mathrm{K}-\mathrm{ATPase}$ activity are presented in Table 1 .

Total intracellular ATP content and metabolic origin of intracellular ATP. The total ATP content in fibroblasts derived from patients with cystinosis was decreased compared with the healthy controls (median, 38.8 [range, 26.9-72.1] versus median, 51.5 [range, $44.7-58.5] \mathrm{nmol} / \mathrm{mg}$ protein, $p<$ $0.05)$. No significant correlation could be detected between intracellular cystine accumulation and intracellular ATP content (Fig. 1). Additionally we determined intracellular ATP content in polymorphonuclear leukocytes isolated directly from patients with cystinosis $(n=15)$ treated with cysteamine $(40-60 \mathrm{mg} / \mathrm{kg} / \mathrm{d})$ and compared the values with those derived from control subjects $(n=18)$. As in cultured cystinotic fibroblasts, we detected a significant decrease of intracellular ATP content in cystinotic versus control cells (median, 317 [range, 149-1141] versus median, 557 [range, 207-1101] $\mathrm{nmol} / \mathrm{mg}$ protein, $p<0.05$ ) and no correlation between the intracellular cystine and ATP content (Fig. 2).

To investigate the relative contribution of glycolysis and mitochondrial oxidative phosphorylation for ATP synthesis in cultured fibroblasts, we determined the intracellular ATP content after incubation of the cells with the inhibitors of glycolysis (SIA, 2-DOG) and respiratory chain complexes (rotenone and antimycin A). Before determination of intracellular ATP content, a cell viability test was performed showing that, under the used conditions, the majority of cells (>90\%) remained viable (data not shown).

As demonstrated in Figure 3, inhibition of the glycolysis resulted in a remarkable decrease $(>80 \%)$ of intracellular ATP content compared with vehicle control in both cystinotic and control fibroblasts. After the inhibition of complex I by rotenone or complex III by antimycin, less than $30 \%$ decline of initial intracellular ATP content was observed in cystinotic and control fibroblasts. Cystinotic fibroblasts exhibited a slightly more pronounced decline of intracellular ATP content

Table 1. Intracellular cystine and ATP content (nmol/mg protein); activity of respiratory chain enzyme complexes I, II, III ( $\mathrm{mU} / \mathrm{mU}$ $\mathrm{COX})$, and IV (mU/U CS); and activity of Na,K-ATPase (nmol/mg protein/h) in cultured skin fibroblasts

\begin{tabular}{lccc}
\hline & $\begin{array}{c}\text { Cystinosis } \\
(n=8)\end{array}$ & $\begin{array}{c}\text { Controls } \\
(n=8)\end{array}$ & $p$ \\
\hline Cystine & $4.3(2.7-5.5)$ & $0.2(0.1-0.3)$ & $<0.001$ \\
ATP & $38.8(26.9-72.1)$ & $51.5(44.7-58.5)$ & $<0.05$ \\
Complex I & $158(91-223)$ & $162(97-220)$ & 0.3 \\
Complex II & $922(685-1139)$ & $982(744-1230)$ & 0.9 \\
Complex III & $1513(1179-2000)$ & $1429(1300-1841)$ & 0.8 \\
Complex IV & $957(846-1281)$ & $930(764-1151)$ & 0.4 \\
Na,K-ATPase & $50.8(32.1-89.0)$ & $60.5(45.6-95.0)$ & 0.3 \\
\hline
\end{tabular}

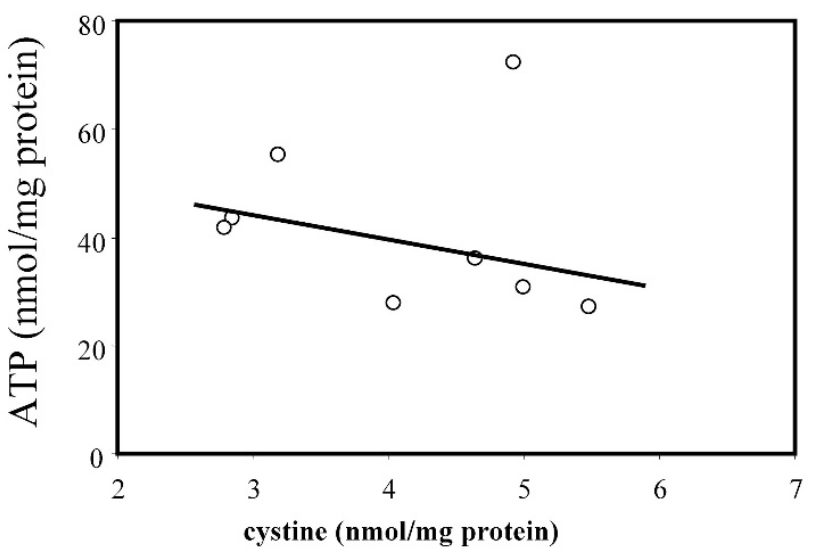

Figure 1. Intracellular cystine and ATP content in fibroblasts of patients with cystinosis $(n=8, r=-0.45, p=0.3)$.

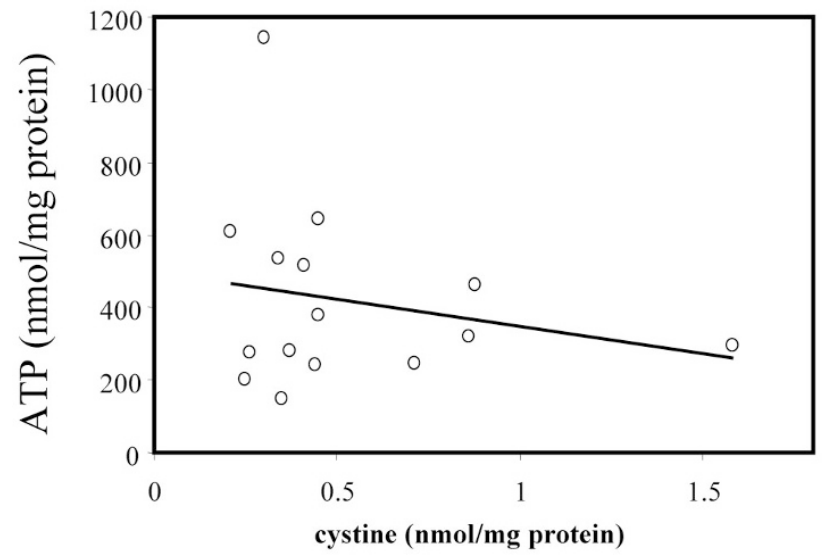

Figure 2. Intracellular cystine and ATP content in polymorphonuclear leukocytes of patients with cystinosis $(n=15, r=-0.02, p=0.9)$.

due to the inhibition of respiratory chain complexes, but the difference with controls did not reach statistical significance (Fig. 3).

Overall energy-generating capacity and activity of respiratory chain complexes of isolated mitochondria and ATP production rate in intact cells. As shown in Table 2, comparable overall oxidation rates of $\left[1-{ }^{14} \mathrm{C}\right]$-pyruvate, $\left[1-{ }^{14} \mathrm{C}\right]-2$ oxoglutarate, $\left[\mathrm{U}-{ }^{14} \mathrm{C}\right]$-malate, and $\left[1,4-{ }^{14} \mathrm{C}\right]$-succinate in isolated mitochondria were detected in cystinotic $(n=4)$ and control fibroblasts $(n=4)$.

The activity of individual mitochondrial respiratory chain complexes did not differ between cystinotic and control cells (Table 1).

Furthermore, maximal bradykinin-induced increase of mitochondrial ATP production measured in intact cells by intramitochondrial luciferase probe was not different between cystinotic $(n=3)$ and control $(n=4)$ fibroblasts (Fig. 4).

Na,K-ATPase activity. Although the activity of $\mathrm{Na}, \mathrm{K}$ ATPase, measured by ouabain-sensitive $\mathrm{Rb}$ influx, was slightly decreased in cystinotic cells (median, 50.8 [range, 32.1-67.0] versus median, 60.5 [45.6-95.0] nmol/mg protein/ h), this difference was not statistically significant (Table 1). 


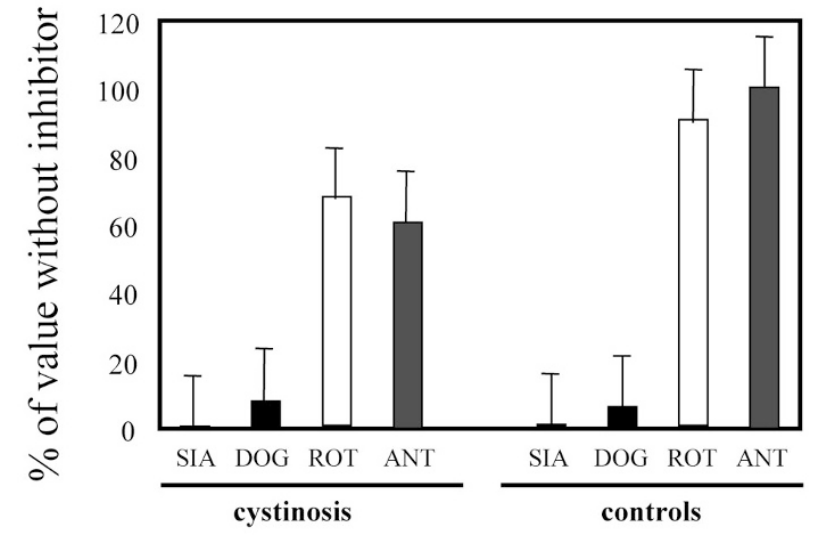

Figure 3. Decrease in intracellular ATP content (mean, SD) after inhibition of glycolysis (sodium iodoacetate [SIA], 2-deoxyglucose [DOG]) and respiratory chain complexes (I: rotenon [ROT]; III: antimycin A [ANT]) in cystinotic $(n=4)$ and control $(n=5)$ fibroblast cell lines $(p>0.05)$.

Table 2. ${ }^{14} \mathrm{CO}_{2}$ production rate $\left(\mathrm{nmol}{ }^{14} \mathrm{CO}_{2} / h\right)$ from $\left[{ }^{14} \mathrm{C}\right]$ citric cycle intermediates in cultured skin fibroblasts

\begin{tabular}{llll}
\hline & \multicolumn{1}{c}{$\begin{array}{c}\text { Cystinosis } \\
(n=4)\end{array}$} & $\begin{array}{c}\text { Controls } \\
(n=4)\end{array}$ & $p$ \\
\hline$\left[1-{ }^{14} \mathrm{C}\right]-$-Pyruvate + malate & $922(717-1332)$ & $706(567-1278)$ & 0.3 \\
{$\left[1-{ }^{14} \mathrm{C}\right]-$ Pyruvate + carnitine } & $801(690-1252)$ & $664(550-1326)$ & 0.3 \\
{$\left[1-{ }^{14} \mathrm{C}\right]-2-$-Oxoglutarate } & $454(276-539)$ & $291(226-488)$ & 0.3 \\
{$\left[\mathrm{U}-{ }^{14} \mathrm{C}\right]-$ Malate + pyruvate } & $430(374-1517)$ & $469(317-1368)$ & 0.9 \\
{$\left[1,4-{ }^{14} \mathrm{C}\right]-$ Succinate + pyruvate } & $232(191-325)$ & $261(216-286)$ & 0.7 \\
\hline
\end{tabular}

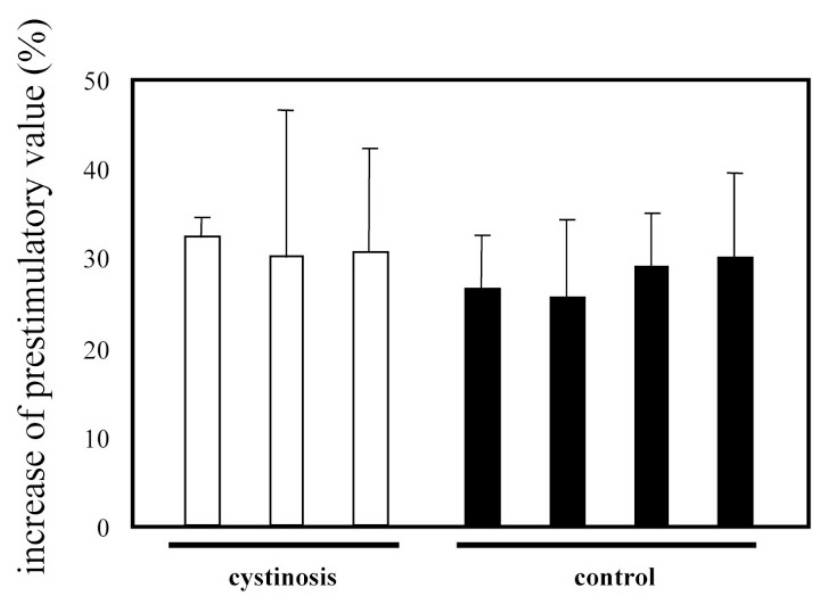

Figure 4. Maximal bradykinin-induced increase in mitochondrial ATP production (mean, SD) in different cystinotic $(n=3)$ and control $(n=4)$ fibroblast cell lines $(p>0.05)$.

\section{DISCUSSION}

Cystinosis is the most frequent cause of inherited Fanconi syndrome, leading to renal failure, the pathogenesis of which is still unknown. Based on the studies of rat and rabbit proximal tubular suspensions or cultured proximal tubular cells loaded with CDME, intracellular ATP depletion with subsequent decrease of Na,K-ATPase activity has been proposed to be the underlying biologic mechanism of cellular dysfunction in cystinosis (12-15). Inhibited energy metabolism, however, has not yet been demonstrated in human cystinotic material. Here, for the first time, we attempted to confirm such an alteration of intracellular ATP status and oxidative phosphorylation in cystinosis by an extensive study of the energy metabolism in human cystinotic fibroblasts. Intracellular ATP content was decreased in fibroblasts derived from patients with cystinosis compared with the controls. Because the metabolism of cultured cells could be influenced by ex vivo growth and because of the overlap of ATP ranges between cystinotic and control cells, we additionally determined intracellular ATP content in polymorphonuclear leukocytes immediately isolated from freshly drawn blood. Interestingly, in agreement with the fibroblast data, intracellular ATP was also decreased in polymorphonuclear leukocytes of the patients compared with the controls, despite the fact that their cystine values were decreased compared with the fibroblasts due to cysteamine treatment.

Intracellular ATP is produced by cytosolic glycolysis and mitochondrial OXPHOS. In vivo studies demonstrated that energy of mammalian kidneys is mostly derived from the oxidative metabolism. The activity of glycolytic enzymes in proximal tubules is minimal (3). In contrast, the contribution of oxidative phosphorylation for ATP production is limited in cultured skin fibroblasts (30), which was confirmed in this study. Cystinotic fibroblasts were, however, chosen as the subject of our study because they accumulate cystine in vitro and therefore will exhibit the metabolic consequences thereof. Second, cultured fibroblasts from patients with mitochondrial disorders have been successfully used to demonstrate reduced ATP production and deficient OXPHOS activity $(26,31,32)$. Additionally, an inhibited activity of Na,K-ATPase after CDME loading has been demonstrated in cultured LLC-PK1 cells (15), despite the fact that these cells are also predominantly glycolytic (33).

Several approaches were used to investigate mitochondrial ATP-generating capacity of cystinotic and control fibroblasts. Initial experiments were performed in isolated mitochondria. Overall mitochondrial energy-generating capacity, as well as the activity of individual mitochondrial respiratory chain complexes (I, II, III, IV), was comparable between cystinotic and control cells, providing evidence that intracellular cystine accumulation did not cause an evident mitochondrial defect.

Assuming that the presence of high lysosomal cystine content in the cell is obligatory for the alteration of oxidative phosphorylation, additional experiments were performed in intact cells to study bradykinin-stimulated intramitochondrial ATP production. These experiments, however, did not reveal any difference between cystinotic and control fibroblasts. In summary, altered mitochondrial ATP-generating capacity was not responsible for decreased ATP content in cystinotic fibroblasts.

The slightly more pronounced decline of intracellular ATP after the inhibition of the respiratory chain complexes in cystinotic fibroblasts might indicate the inhibition of glycolytic activity or a relative higher contribution of the OXPHOS system. Elevated ATP consumption could be an alternative explanation of decreased ATP content in cystinotic cells; however, this possibility was not examined in this study.

Finally, we examined whether intracellular ATP decrease in cultured fibroblasts caused a functional inhibition of the ac- 
tivity of Na,K-ATPase. The conditions of rubidium uptake experiments (low sodium and physiologic potassium concentrations in the medium) were carefully selected to stimulate the maximal activity of $\mathrm{Na}, \mathrm{K}$-ATPase, which was found to be comparable in cystinotic and control cells. This might be different in proximal tubular cells because $\mathrm{Na}, \mathrm{K}$-ATPase activity in fibroblasts is trivial compared with proximal tubular cells in vivo (3).

How do we reconcile our findings with the results obtained in proximal tubules loaded with CDME? It is not excluded that CDME loading can provoke effects different from those attributed to cystine accumulation in cells with a deficient lysosomal cystine carrier. In concordance with this idea, recent work on human IHKE-1 cells demonstrated that CDME itself had an acute (within $1 \mathrm{~min}$ ) effect on the basal membrane potential (an initial depolarization followed by a more pronounced repolarization). This effect was distinct from those on $\mathrm{Na}^{+}$-dependent alanine transporter, which was inhibited after at least $30 \mathrm{~min}$ of incubation with CDME. As the hyperpolarization induced by CDME could be blocked by $\mathrm{Ba}^{2+}$, the authors concluded that CDME activated a $\mathrm{K}^{+}$conductance (34).

It is also possible that CDME can directly affect the mitochondrial respiration because the incubation of isolated mitochondria with CDME resulted in reduced mitochondrial $\mathrm{O}_{2}$ consumption with glutamate as substrate, but not with succinate, by which electrons enter the electron transport chain beyond complex I at the level of coenzyme $\mathrm{Q}_{10}$, suggesting the direct inhibition of complex I by CDME (35).

An increase in intracellular cysteine concentration was demonstrated in vivo in rats after $4 \mathrm{~d}$ of intraperitoneal CDME injections and in rabbit proximal tubules loaded with CDME in vitro probably as a result of reduction of cystine to cysteine in the cytosol (11). To determine whether cystine or its breakdown product cysteine was responsible for alterations in proximal tubular transport, the effect of cysteine dimethyl ester loading was studied. Strikingly, cysteine ester could indeed inhibit volume absorption, glucose and bicarbonate transport in rabbit proximal tubules in a concentrationdependent manner, while methyl esters of leucine and tryptophan had no effect on these parameters (12). In contrast to CDME, cysteine ester loading, however, did not affect the $\mathrm{O}_{2}$ consumption rate, despite a remarkable increase in intracellular cysteine concentration (36).

More research is required for the understanding of the pathogenesis of cystinosis. This research should further explore already introduced alternative pathogenic mechanisms of the disease as enhanced apoptosis and possibly increased reactive oxygen cell damage (37-39). New techniques such as microarrays and proteomics applied in human in vitro models of cystinosis might help to create new ideas for the future studies. Human proximal tubular cells from cystinotic patients can be cultured in vitro (40) and possibly represent an excellent model for studying the pathogenesis of the disease. However, the metabolism of these cells can be influenced by ex vivo growth. In addition, cultures from urine cells might contain other than proximal tubular epithelial renal cells, including glomerular podocytes, which can be exfoliated to urine. This would mean that before the transport and metabolic studies, the cells from urine should be cloned to obtain a pure proximal cell culture.

In conclusion, intracellular ATP depletion in cultured human cystinotic fibroblasts is not caused by the alteration of mitochondrial oxidative phosphorylation and does not result in a functional inhibition of Na,K-ATPase activity. Study of proximal tubular cells derived from patients with cystinosis is required to explain the discrepancy of our results with those obtained in CDME loading model of cystinosis.

Acknowledgments. We are grateful to Dr. W. Feitz and Dr. R. De Gier for helping in obtaining control material.

\section{REFERENCES}

1. Kalatzis V, Cherqui S, Antignac C, Gasnier B 2001 Cystinosin, the protein defective in cystinosis, is a $\mathrm{H}^{+}$-driven lysosomal cystine transporter. EMBO J 20:5940-5949 2. Gahl WA, Thoene JG, Schneider JA 2002 Cystinosis. N Engl J Med 347:111-121

3. Klahr S, Hamm LL, Hammerman MR, Mandel LJ Renal metabolism: integrated responses. In: Windhacer EE (ed) Handbook of Physiology. Section 8: Renal Physiology. Oxford University Press, New York, pp 2262-2333.

4. Niaudet P, Rotig A 1996 Renal involvement in mitochondrial cytopathies. Pediatr Nephrol 10:368-373

5. Schulman JD, Bradley KH, Seegmiller JE 1969 Cystine: compartmentalization within lysosomes in cystinotic leukocytes. Science 166:1152-1154

6. Goldman R, Kaplan A 1973 Rupture of rat liver lysosomes mediated by L-amino acid esters. Biochim Biophys Acta 318:205-216

7. Reeves JP 1979 Accumulation of amino acids by lysosomes incubated with amino acid methyl esters. J Biol Chem 254:8914-8921

8. Gahl WA, Tietze F, Bashan N, Steinherz R, Schulman JD 1982 Defective cystine exodus from isolated lysosome-rich fractions of cystinotic leucocytes. J Biol Chem 257:9570-9575

9. Jonas AJ, Smith ML, Schneider JA 1982 ATP-dependent lysosomal cystine efflux is defective in cystinosis. J Biol Chem 257:13185-13188

10. Pisoni RL, Thoene JG, Christensen HN 1985 Detection and characterization of carrier-mediated cationic amino acid transport in lysosomes of normal and cystinotic human fibroblasts. Role in therapeutic cystine removal? J Biol Chem. 260:47914798

11. Foreman JW, Bowring MA, Lee J, States B, Segal S 1987 Effect of cystine dimethylester on renal solute handling and isolated renal tubule transport in the rat: a new model of the Fanconi syndrome. Metabolism 36:1185-1191

12. Salmon RF, Baum M 1990 Intracellular cystine loading inhibits transport in the rabbit proximal convoluted tubule. J Clin Invest 85:340-344

13. Coor C, Salmon RF, Quigley R, Marver D, Baum M 1991 Role of adenosine triphosphate (ATP) and NaK ATPase in the inhibition of proximal tubule transport with intracellular cystine loading. J Clin Invest 87:955-961

14. Baum M 1998 The Fanconi syndrome of cystinosis: insights into the pathophysiology. Pediatr Nephrol 12:492-497

15. Ben-Nun A, Bashan N, Potashnik R, Cohen-Luria R, Moran A 1993 Cystine loading induces Fanconi's syndrome in rats: in vivo and vesicle studies. Am J Physiol 265:F839-F844

16. Guillet G, Sassolas B, Fromentoux S, Gobin E, Leroy JP 1998 Skin storage of cystine and premature skin ageing in cystinosis. Lancet 352:1444-1445

17. Levtchenko E, de Graaf-Hess A, Wilmer M, van den Heuvel L, Monnens L, Blom H 2004 Comparison of cystine determination in mixed leukocytes vs polymorphonuclear leukocytes for diagnosis of cystinosis and monitoring of cysteamine therapy. Clin Chem 50:1686-1688

18. Yang Y, Balcarcel RR 2004 96-well plate assay for sublethal metabolic activity. Assay Drug Dev Technol 2:353-361

19. Dickman KG, Mandel LJ 1990 Differential effects of respiratory inhibitors on glycolysis in proximal tubules. Am J Physiol 258:F1608-F1615

20. Bentlage HA, Wendel U, Schagger H, ter Laak HJ, Janssen AJ, Trijbels JM 1996 Lethal infantile mitochondrial disease with isolated complex I deficiency in fibroblasts but with combined complex I and IV deficiencies in muscle. Neurology 47:243-248

21. Trijbels JM, Janssen AJ, van den Heuvel LP, Sengers RC, Smeitink JA 2004 Biochemical diagnosis of OXPHOS disorders. In: Smeitink JA, Sengers RC, Trijbels JM, Kluwer (eds) Oxidative Phosphorylation in Health and Disease. Academic/ Plenum Publishers, New York, pp 79-94.

22. Fischer JC, Ruitenbeek W, Trijbels JM, Veerkamp JH, Stadhouders AM, Sengers RC, Janssen AJ 1986 Estimation of NADH oxidation in human skeletal muscle mitochondria. Clin Chim Acta 155:263-273

23. Fischer JC, Ruitenbeek W, Berden JA, Trijbels JM, Veerkamp JH, Stadhouders AM, Sengers RC, Janssen AJ 1985 Differential investigation of the capacity of succinate oxidation in human skeletal muscle. Clin Chim Acta 153:23-36 
24. Cooperstein SJ, Lazarow A 1951 A microspectrophotometric method for the determination of cytochrome oxidase. J Biol Chem 189:665-670

25. Srere PA 1963 Citryl-CoA A substrate for the citrate-cleavage enzyme. Biochim Biophys Acta 73:523-525

26. Visch HJ, Rutter GA, Koopman WJ, Koenderink JB, Verkaart S, de Groot T, Varadi A, Mitchell KJ van den Heuvel LP, Smeitink JA, Willems PH 2004 Inhibition of mitochondrial $\mathrm{Na}+-\mathrm{Ca} 2+$ exchange restores agonist-induced ATP production and $\mathrm{Ca} 2+$ handling in human complex I deficiency. J Biol Chem 279:40328-40336

27. Ainscow EK, Rutter GA 2001 Mitochondrial priming modifies $\mathrm{Ca} 2+$ oscillations and insulin secretion in pancreatic islets. Biochem J. 353:175-180

28. Jouaville LS, Pinton P, Bastianutto C, Rutter GA, Rizzuto R 1999 Regulation of mitochondrial ATP synthesis by calcium: evidence for a long-term metabolic priming. Proc Natl Acad Sci U S A 96:13807-13812

29. Munzer JS, Daly SE, Jewell-Motz EA, Lingrel JB, Blostein R 1994 Tissue- and isoform-specific kinetic behavior of the Na,K-ATPase. J Biol Chem 269:16668-16676

30. Robinson BH 1996 Use of fibroblast and lymphoblast cultures for detection of respiratory chain defects. Methods Enzymol 264:454-464

31. Loeffen JL, Smeitink JA, Trijbels JM, Janssen AJ, Triepels RH, Sengers RC, van den Heuvel LP 2000 Isolated complex I deficiency in children: clinical, biochemical and genetic aspects. Hum Mutat 15:123-134

32. Ugalde C, Janssen RJ, van den Heuvel LP, Smeitink JA, Nijtmans LG 2004 Differences in assembly or stability of complex I and other mitochondrial OXPHOS complexes in inherited complex I deficiency. Hum Mol Genet 13:659-667
33. Felder E, Jennings P, Seppi T, Pfaller W 2002 LLC-PK(1) cells maintained in a new perfusion cell culture system exhibit an improved oxidative metabolism. Cell Physiol Biochem 12:153-162

34. Cetinkaya I, Schlatter E, Hirsch JR, Herter P, Harms E, Kleta R 2002 Inhibition of $\mathrm{Na}(+)$-dependent transporters in cystine-loaded human renal cells: electrophysiological studies on the Fanconi syndrome of cystinosis. J Am Soc Nephrol 13:20852093

35. Foreman JW, Benson LL, Wellons M, Avner ED, Sweeney W, Nissim I, Nissim I 1995 Metabolic studies of rat renal tubule cells loaded with cystine: the cystine dimethylester model of cystinosis. J Am Soc Nephrol 6:269-272

36. Sakarcan A, Timmons C, Baum M 1994 Intracellular distribution of cystine in cystine-loaded proximal tubules. Pediatr Res 35:447-450

37. Park M, Helip-Wooley A, Thoene J 2002 Lysosomal cystine storage augments apoptosis in cultured human fibroblasts and renal tubular epithelial cells. J Am Soc Nephrol 13:2878-2887

38. Chol M, Nevo N, Cherqui S, Antignac C, Rustin P 2004 Glutathione precursors replenish decreased glutathione pool in cystinotic cell lines. Biochem Biophys Res Commun 324:231-235

39. Levtchenko E, de Graaf-Hess A, Wilmer M, van den Heuvel L, Monnens L, Blom H 2005 Altered status of glutathione and its metabolites in cystinotic cells. Nephrol Dial Transplant 20:1828-1832

40. Laube GF, Haq MR, van't Hoff WG 2005 Exfoliated human proximal tubular cells: a model of cystinosis and Fanconi syndrome. Pediatr Nephrol 20:136-140 